\title{
A QUANTITATIVE APPROACH TOWARDS BUSINESS-TO-EMPLOYEE MANAGEMENT AND ITS IMPACT ON ORGANIZATION
}

\author{
MRS. PRIYADARSHINI JAIN
}

Department of Management, Glocal University, Saharanpur, Uttar Pradesh, India

\begin{abstract}
The established e-business literature body focuses mainly on e-business types of Business-to - Business (B2B) and Business-to-Consumers (B2C). By contrast, in the scholarly literature, Business-to-Employee (B2E) is relatively less emphasised. This reflects an evolving field, considering the lack of interest paid to B2E programs, and has the power to influence organizations substantially. B2E systems typically employ intercorporate networks that enable businesses to provide valuable services, knowledge or products for their dispersed employees. Regrettably, their usage in organizational environments has not been objectively examined and published in the existing academic literature amid an increasing need for incorporating B2E solutions. It was argued that evaluating employees' use of B2E solutions is a major concerned topic of research because it is unlikely that the advantage emerging from introducing such solutions will be realized when they are not satisfactorily transferred among employee community. The study results offer insightful explanations of the effect of many variables on the employees' low usage of the site. More precisely, portal usefulness was shown to be a dynamic concept composed essentially of two prevailing aspects all of which are in effect affected by organization help. The discovery of these dimensions denotes a significant contribution to this work.

KEYWORDS: Business-to-Business, Business-to-Consumers, Business-to-Employee, E-Business
\end{abstract}

Received: Jun 08, 2020; Accepted: Jun 28, 2020; Published: Sep 08, 2020; Paper Id.: IJMPERDJUN20201104

\section{INTRODUCTION}

B2E programs typically utilize intra-business networks to allow companies to provide their scattered workers with valuable resources, knowledge or goods. B2E allows quick access to related knowledge, resources, and goods help to create a contentstaff that is predictable to be additional organizationally faithful. These programs often help companies reduce their operating costs by streamlining employee-related procedures and reducing filing, email, mailing, and travel-related expenses. Adopting B2E e-business programs will also help companies outperform rivals by bringing their workers together.Regrettably, their usage in organizational environments has not been objectively examined and published in the existing academic literature amid an increasing need for incorporating B2E solutions. It was argued that evaluating employees' use of B2E solutions is a major concerned topic of research because it is unlikely that the advantage emerging from introducing such solutions will be realized If the workplace culture is not effectively relocated. Directors should also be aware of issues which may have important implications on the use of their companies of e-business B2E applications. Against this literature, universities' experience of implementing an employee portal has been documented by examining a portion of university staff's views of the impacts of popularly debated variables on their portal use behaviour[1].

The management of information in health facilities is unique of the maincontests for theOperative growth and success of organization. Information and communication technologies (ICT) are important for the dissemination, exchange and interpretation of knowledge in our global health-care setting. In an area like the "McGill University Health 
Center" (MUHC), an e-commerce B2E system reflects the shift from conventional to interactive exchange modes for the 13,000 workers of the institution. This literature argues that a model of e-commerce will provide substantial opportunities for the simple and open production, exchange and distribution of inter-professional expertise and information[2].

The study of a number of researchers who analyzed issues such as usability and design problems related to the different types of digital B2C portals that are very close to employee portals is cited from current e-business literature. Researchers consider this correlation but contend that there are significant variations among B2C porches and workerporches in areas such as the number of users, the degree of access to portal organizational controls, and the number of services and information provided Consequently, since employee portal intentions and objectives vary from B2C virtual portals (although much of the underlying technological problems are similar), we may assume that employee portal use activity is distinct from that of B2C portal users. Investigators have thus narrowed our exposure to literature review to just the B2E schemes[3].

Employee interfaces have entered a degree of growth that needs the understanding of growing expenditures offer significant benefits for both the end consumer and the company. This paper seeks to build a deeper understanding of the functionality of an employee portal. We plan to apply this study to the topic in question through the multiusers review carried out by the researchers and their colleagues, focused on the implementation paradigm of the McLean knowledge method, in a single Portuguese banking sector group. They implemented the established model in a survey of more than 3000 responses and decided on its applicability, given the constraints indirect.The analysis empirically authenticates the idea and shows that it corresponds to the suggested case, thus suggesting the most significant considerations to be involved in the creation of portals for employees. Implications of the results are explored, and a framework is provided for more work in this area[4].

An analysis of the published studies relating to B2E structures identifies three different research aspects of concern from scholars:Decisions on implementing B2E systems, gains from implementing B2E systems and employee satisfaction with B2E systems. Usually, the first two topics are discussed from a management perspective. The third dimension of this process has taken on the opinions of individual workers on the performance of B2E systems. Many researchers compared success in the form of gratification and examined the consummation of the employee with different methods of B2E schemes in the context multi-factor perfect.For ex; in a Taiwanese company, few researchers analysed employee satisfaction with a B2E benefit system and found that factors like comfort, functionality, precision, cost, and safety affected employee satisfaction with the application. Researchers have planned a perfect to assess user fulfilmentthrough the portal of employees and defined 8 variables which could influence portal satisfaction of employees. They empirically evaluated this model in a broad university environment in a subsequent analysis and noticed that five variables, including utility, ease of usage, portal, anonymity and usability of the workplace portals that influenced customer retention[3].

Within the HR literature the implementation of different types of employee-related info systems was addressed. Through the viewpoint of individual workers, a community of HR researchers absorbedscheduled the adoption and use of HR information systems. They considered individual employee characteristics and their behaviours to be predictors of the adoption and eventual use of HR based infoschemes by employees.A significant portion of this section deals with the factors that affect the decisions of individual sales workers to use automated systems. Such research widely recognized that perceived benefits are a key factor in the practical use of automation systems by salespeople. In fact, demographic 
characteristics of the sales force also affect the acceptance and even use of sales automation technologies.

Researchers have proposed a Technology Adoption Model (TAM) to Answer the explanation why users accept or deny IT. The model reveals that perceived efficiency and utility are the two most significant factors in recognizing the use of information technology by people. The model suggests that More recently, a new TAM variant known as TAM2 is being introduced that incorporates subjective criteria and has been tested using quantitative study designs. Many researchersdescribed TAM model in describing how Specific forms of IT systems in enterprises are used. Nevertheless, observational TAM research is not completely definitive[5].

The acceptance and dissemination of innovation literature explores how innovation spreads through the market from the moment it is launched. Nonetheless, the acceptance process may start shortly after this resistance is overcome if a technology meets current barriers.If it is not possible to break down the resistance, adoption will slow down and innovation will likely fail. According to researchers, disapproval of an innovation sometimes occurs even after a person adopts an innovation.Two significant reasons for innovation rejection have been identified: a) a technology is rejected because of its results dissatisfaction, and b)When an idea that was originally considered appealing was ultimately discovered to be inconsistent with people's values. An early research study showed recognition and resistance to innovation usage contribute to the innovativeness of a person[6].

These literature sources understand that the choice of an separateworker to approve and use an IT request is affected by many variables. They include employee demographics, employee preparedness, technological features, employee-perceived usefulness of the system, usefulness and ease of use, employee attitudes to the IT system among others. Researchers note that in the e-business literature, it is implicitly presumed that decisions taken by senior management are likely to lead to rapid dissemination among the workforce of B2E technologies.Therefore, researchers have stopped instead of asking for a study of workplace utilization habits in organisations with B2E programs. They agree that the variables found from various B2E linked literature sources are valuable for analysing employees' usage of such programs. However, because work in this field is practically non-existent, more study into the usage of B2E portals must be dedicated. In line with this request, this work has been conducted to understand how specific influences have affected workers inside the university to utilize B2E portals.By doing so, they have followed an exploratory analysis methodology and using the variables (as mentioned above) and as a reference by previous studies to direct current work[7].

Business to Employee (B2E) programs are e-business solutions leveraging an intra-business network that helps companies to connect their workers with products / services. Such programs provide an effect on staff retention and success in organization. Company literature illustrates the benefits companies benefit by adopting B2E programs. However, scientific research has devoted little attention to recognizing the effect of these structures. Consequently, The effect on achieving the advantages of B2E systems is not understood as to what causes. His thesis explores the experience of an Australian university with the creation of an ESS portal and highlights some lessons. [8].

The results of digital innovation bring into doubt conventional project environments and corresponding procedures, informed by information development, start-up technology and the viewpoint of architecture. The problem confronting today's existing companies is how the exponential growth of technology will increase working time for digital product performance. Researchersconsequently seek to deepen comprehension of how effective digital innovation initiatives are organized in 6 dimensions (subject, entity, resources, laws, society, labour division).To this end, researchers rely on operation theory to examine nine established firms' ventures in the business-to-employee sense about their method 
of managing digital-age innovation function. Based on the qualitative case study, they include a collection of criteria within the 6 dimensions focused on the principle of action required to reshape the framework of novelty initiatives with a numerical result in obligatory businesses[9].

The staff and visitors are well known to have regular interaction during the production of H\&L company goods and services. Do you realize how the disposition and willingness of an employee to offer high quality customer affects the experience of guests? A new research conducted by the Hotel and Restaurant Administration Review at Cornell University indicates that there is a positive connection between staff happiness and guest satisfaction. The most closely associated variables were whether the employees were polite, efficient and attentive to the visitors, and whether the employees were sensitive, compassionate and helpful in delivering their services to the workers.In the cruise line market, for example, where businesses tend to leapfrog each other with bigger, smaller, and more sophisticated ships, the distinction boils down to quality to customers. Adam Goldstein, the senior vice president for Hotel Operations at Royal Caribbean International, "In today's service setting, employee and guest loyalty are inseparable. They need to provide happy workers who are experienced and well qualified to have world-class guest service. "Remarks Bjorn Hanson, global leader of Price Water House Coopers H\&L," In H\&L firms, employee recruiting, retention and growth are getting more focus than it has ever been.There are expense issues but the capacity to do so is far more critical than qualitysuperior guest service rates to a sufficiently qualified, disciplined, educated, paid, and empowered workforce[10].

The study results offer insightful explanations of the effect of many variables on the employees' low usage of the site. More precisely, portal usefulness was shown to be a dynamic concept composed essentially of two prevailing aspectsall of which remaintrendy effect affected by organization help. The detection of these sizes denotes a significant influence to this work.

\section{METHODOLOGY}

\section{Design}

University is the contributing case organisation; the collection is driven byillustrative approach theory, regardless of our aim to demonstrate the consequences of variables that may be found in an enterprise that has made a significant effort to implement a B2E program. In addition, portals with B2E are reported to have recently launched and, thus, a tertiaryindustry association is very appropriate because they continue to provide a dispersed workforce on several campuses.

\section{Sample}

A sample questionnaire was established that provided a series of things that work multiple short-listed variables centred on previous qualitative analysis and worksappraisal. This surveyremained circulated amongst the 400 University employees concerned. A total of 160 replies resulting in a response rate of 28.2 percent were obtained.

\section{Instrument}

Based on the knowledge of prior qualitative research including multiple primary participants from Total three variables (along with 2 other shortlisted variables) have been used by the Portal Steering Committee in the survey questionnaire. The survey questionnaire contained the elements required to calculate seven variables. Concentrate just on those 3 variables identified to be highly valuable were limited in the previous research.Table 1 gives a description of how these three variables were calculated, anda theoretical rationale is given in favour of the association between these considerations and the usage of the B2E portals by employees. Every element was calculated in a scale of 1 to 5 , where 1 is really negative, 2 
means competition, 3 is a positive thing, 4 is harmony and 5 is a solid agreement. The dependent variable (use of the B2E portal), was estimated from five points in the interval, where 1 is rarely used; 2 is rarely used every three months at least once, 3 is not less than once a month, 4 is uncommon once a fortnight and 5 is less than once a week. Three domain experts checked the survey tool, and some adjustments were made introduced.

\section{Data Analysis}

An exploratory factor review was conducted to resolve the cogency of the tool comprising 13elements representing 2issues (as stated in Table 1). The findings as a 4-factor solution has been developed are very important. A quick look at the results of the factor analysis reveals that out of 13 products, 3 were omitted because Across 2 reasons they loaded heavily. Nonetheless, a notable finding is that the perceived effectiveness of the portal can be considered to be of two types: perceived teamwork utility and perceived usefulness of sharing information. Reliability of items which were eventually holding after Cronbach alpha factor analysis was tested and obtained to be very acceptable because they had values of 0.71 and are seen in Table 2 .

Table 1: The Collection of Sources for the Factors which are to be Measured

\begin{tabular}{|l|c|c|}
\hline \multicolumn{1}{|c|}{ Factors } & No. of Elements & Resources \\
\hline Perceived utility of portals & 9 & \multirow{2}{*}{ Introduced by researchers } \\
\hline Perceived training & 2 & \\
\hline Aid seen in management & 3 & \\
\hline
\end{tabular}

Table 2: The Result's Reliability of the Gauges for the Issues' Utility

\begin{tabular}{|l|c|c|}
\hline \multicolumn{1}{|c|}{ Factors } & Dependability & Elements Involved \\
\hline $\begin{array}{l}\text { Apparent utility of transmitting } \\
\text { knowledge }\end{array}$ & 0.71 & 3 - PU $(2,5,6)$ \\
\hline Aid seen in management & 0.811 & 2 - MS $(2,3)$ \\
\hline Perceived utility of collaboration & 0.765 & 5 - PU $(1,3,4,7,9)$ \\
\hline Witnessed preparation & 0.739 & 2 - PT $(1,2)$ \\
\hline
\end{tabular}

\section{RESULTS AND DISCUSSIONS}

Results of the survey show a poor use of the workplace platform as the mean utilization is 3.25 (on a scale of 1 to 5). That implies workers aren't using the app daily. They usually use portals at least once a two-week period. Medium use of portals depends upon gender, managers, non-managers and workers (e.g. administrative, academic and research). The mean use of portals is different. Nonetheless, the variations do not exist statistically (as seen in Table 3).In fact, portal use is not strong in all of these workplace population groups, since the median portal use is well below four.Therefore, the existence of an overall low level of portal usage by university employees was suggested. An important finding is that $8 \%$ of the employees surveyed do not use the portal at all, and that another $18 \%$ of employees use the portal only in a 2-month span. In other terms, 25 per cent of workers had few to no app experiences. By comparison, the app is used daily (at least once a week) by just 18 percent of staff. Therefore, individually, these results are representative of the restricted utilization of University staff's website. Table 4 displays the three independent variables' average values (pictured in Table 2).

Table 3: The Average Values of the Portal's usage by the Employees

\begin{tabular}{|c|c|c|c|c|}
\hline Demographic Characteristics & t-value & Average Usage & p-value & df \\
\hline Male Gender & \multirow{2}{*}{1.059} & 3.25 & \multirow{2}{*}{0.289} & \multirow{2}{*}{158} \\
\hline Female Gender & & 3.12 & & \\
\hline Managerial Job Role & \multirow{2}{*}{-0.479} & 3.14 & \multirow{2}{*}{0.630} & \multirow{2}{*}{158} \\
\hline Non-Managerial Job Role & & 3.28 & & \\
\hline
\end{tabular}




\begin{tabular}{|l|l|l|l|l|}
\hline Academic Type of Job & \multirow{2}{*}{1.55} & 3.42 & 0.109 & 158 \\
\cline { 1 - 1 } & & 3.10 & & \\
\hline
\end{tabular}

The main benefits gained by workers are their willingness to obtain knowledge and utilize the information to facilitate contact with others. Table 4 also shows that workers viewed their senior managers as providing a disappointingly poor degree of help in arranging preparation for workers (average: 2.01) and seminars (average: 1.70).On the topic of portal management assistance, the results of the survey strongly show that workers were dissatisfied with the help they thought their managers provided to render the portal accessible to workers. Employee comments suggest that university administration was not seen as promoting frequent upgrading of applicable database details (mean: 2.82) and incorporation across the system of usable resources (mean: 3.05). The regression study was conducted (as seen in Table 5) and showed that portal use is greatly clarified by all portal usefulness dimensions.

Table 4: The Perceptions of the Employees Regarding the Portal and its Average Rating

\begin{tabular}{|l|c|}
\hline Element overview Perceived utility of the portal: Quest \& Value of Communication & 3.52 \\
PU1: The platform allows me to efficiently carry out contact relevant to the job & 3.35 \\
PU2: I get prepared access to knowledge foundations through the portal & 3.50 \\
PU3: The platform eliminates the time spent on the work of human resources & 3.70 \\
PU4: The app offers me precise details to satisfy my needs & 3.14 \\
PU5: The site offers one point of entry to knowledge relevant to the research & 2.74 \\
\hline Perceived utility of the Portal: importance of cooperation & 2.32 \\
PU6: The app provides facility to communicate with other employees & 3.02 \\
PU7: The site lets me gain job related products easily (e.g. online ordering) & \\
PU8: The database offers knowledge related to positions (e.g., strategic, scholarly, administrative) & 2.01 \\
\hline Perceived preparation for the portal & 1.07 \\
PT1: I was granted the training required for using the portal & 2.85 \\
PT2: I participated at seminars to study how to usage the platform & 3.05 \\
\hline Supporting Leadership & \\
MS1: My team accepts daily upgrading of portal functionality & \\
MS2: My team encourages daily upgrading of relevant site details & \\
\hline
\end{tabular}

Table 5: The Analytical Results of the Regression for the usage of the Portal

\begin{tabular}{|l|c|c|c|c|c|}
\hline & \multicolumn{2}{|c|}{$\begin{array}{c}\text { Coefficients Which Are } \\
\text { Under Standardized }\end{array}$} & $\begin{array}{c}\text { Coefficients Which Are } \\
\text { Standardized }\end{array}$ & Sig. & T \\
\cline { 2 - 6 } & $\begin{array}{c}\text { Standard } \\
\text { Error }\end{array}$ & $\mathbf{B}$ & Beta & Standard Error & B \\
\hline Constant & 0.425 & 0.501 & - & 0.239 & 0 \\
\hline CollUsflns & 0.109 & 0.425 & 0.325 & 0.842 & 0.3 .889 \\
\hline $\begin{array}{l}\text { Management } \\
\text { Setup }\end{array}$ & 0.085 & 0.040 & 0.041 & 0.042 & 0.195 \\
\hline InfoUsflns & 0.102 & 0.210 & 0.170 & 0.842 & 2.040 \\
\hline Training & 0.095 & 0.018 & 0.015 & & 0.195 \\
\hline
\end{tabular}

In comparison, perceived funding for preparation and management was not shown to have an impact on the usage of the site by workers Nevertheless, two more rounds of regression analyses were performed to determine the impact of perceived training and management support on both portal aspects. The findings (Tables 6 and 7) demonstrate that funding for Management is closely correlated with all facets of a study of regression. University employees' limited use of the portal is surprising, given that the portal is in service for about four years. Employee expectations of poor portal interest viewed by workers shone some light to grasp portal poor use. Deteriorationstudy shows that together aspects of gateway effectiveness are strongly linked to the use of the database by the employees. This statement reflects our previously published qualitative work carried out at the similar university after the portal direction-finding committee's point of view 
as well as is compatible with the views expressed in literature on IS / IT Deployment.

Table 6: The Analytical Results of the Regression for the Usefulness of the Portal (Communication and Information)

\begin{tabular}{|l|c|c|c|c|c|}
\hline & \multicolumn{2}{|c|}{$\begin{array}{c}\text { Coefficients Which are } \\
\text { Under Standardized }\end{array}$} & $\begin{array}{c}\text { Coefficients Which are } \\
\text { Standardized }\end{array}$ & Sig. & T \\
\cline { 2 - 6 } & $\begin{array}{c}\text { Standard } \\
\text { Error }\end{array}$ & B & Beta & Standard Error & B \\
\hline Constant & 0.205 & 2.812 & - & 0 & 13.572 \\
\hline $\begin{array}{l}\text { Management } \\
\text { Setup }\end{array}$ & 0.058 & 0.040 & 0.329 & 0 & 4.315 \\
\hline Training & 0.068 & -0.060 & -0.065 & 0.365 & -0.902 \\
\hline
\end{tabular}

Table 7: The Analytical Results of the Regression for the Usefulness of the Portal (Collaboration)

\begin{tabular}{|l|c|c|c|c|c|}
\hline & \multicolumn{2}{|c|}{$\begin{array}{c}\text { Coefficients Which Are } \\
\text { Under Standardized }\end{array}$} & $\begin{array}{c}\text { Coefficients Which Are } \\
\text { Standardized }\end{array}$ & Sig. & T \\
\cline { 2 - 6 } & $\begin{array}{c}\text { Standard } \\
\text { Error }\end{array}$ & B & Beta & Standard Error & B \\
\hline Constant & 0.222 & 1.706 & - & 0 & 7.939 \\
\hline $\begin{array}{l}\text { Management } \\
\text { Setup }\end{array}$ & 0.064 & 0.212 & 0.252 & 0.002 & 3.312 \\
\hline Training & 0.072 & 0.135 & 0.140 & 0.065 & 1.834 \\
\hline
\end{tabular}

According to researchers, perceived utility of the device is a key determinant of people's adoption of technology. Similarly, several researchers who analysed implementation of sales force automation systems recorded that workers were hesitant to use IT applications because they did not view such applications as helpful in carrying out their duties. Therefore, for the B2E portal background, we argue that the inability to jointly provide roles-specific data for core collaboration services and portal services have contributed to a negative view of the utility of the portal 's staff and to its low usage. While management assistance has not explicitly led to portal use, it is strongly linked to all portal functionality measurements. This indicates that staff thought that portal management assistance was poor because portal material and functionality were not only insufficient but often poorly modified. In other words, the total absence of intention of management to comprehend how employees wish to usage the portal to provision their effort is gotten as a serious obstacle to enhancing portal functionality.

The statement is compatible with that of analysts who have established insufficient participation of senior organization as a key issue restricting the implementation of creative IT systems in corporate surroundings. The regression study reveals that the educational requirements of the workforce were not sufficiently addressed by management (as the means score shown in Table 4 is quite low), it did not have any major impact on together portal use and apparent portal capabilities. It could be because the platform is simple to use and comprehend and workers with strong technical skills do not need any funding for preparation.It was concluded that while viewed as low portal usability, it was the absence of complete engagement and involvement by senior management that led to the perceptible reduced usefulness that immediately decided low portal utilization by employees. Themark to which porch functionality is viewed has been affected by management's perception of how workers would prefer to use portal to improve their job. Researchers are therefore arguing for greater management involvement in promoting portal use.

Researchers propose that senior management will assume accountability for ensuring adoption (thus success) in IT systems by putting out a specific goal, sharing the goal with staff and engaging in the cycle in corporate IT policy. The stance is in accordance with the opinions of experts who highly advocate encouragement for top organization and 
engagement in building a supportive interior atmosphere toward promote IT project adoption in organizational sceneries.

\section{CONCLUSIONS}

Contrary to other traditional types of e-business, B2E is an under-investigated initiative in which a large number of organizations around the world have invested in it.As such, e-business scholars have paid inadequate attention, To understand completely how the use of B2E e-business systems has been limited in organizational environments, given its positive effect on companies and their employees. Recent literature on e-business transactions has not linked academic literature to the advantages of commercially accessible e-business products from B2E.However, believing that workers will hurry to adopt different forms of B2E technologies as they are implemented into companies is unacceptable. Researchers therefore objectively examine the university environment with which it has been found to be less than optimal for workers to take up the application. They also describe the reasons that led to the Portal 's restricted use. While these considerations were mentioned in different sources of relevant literature, there was no clear examination of their relevance to the B2E portal sense.

The current research thus makes a significant contribution to improving the explanatory capacity of the variables to properly identify the troublesome condition of the database used by the university involved. Additionally, they have given information in their studies, explore two different aspects of portal usability and analyse their relationships with management help. That unique finding was not published in the literature.In conclusion, they think that the study would alert the e-business organizations and IT administrators to the implementation of staff portals. There are therefore certain drawbacks to the analysis. They did not investigate the effect of personal characteristics of workers in understanding their poor portal use. Additional studies are suggested to discuss how certain factors can influence the use of the portal by employees. To investigate this interesting aspect further studies are recommended. Ultimately, this research needs to be repeated in other business sectors to assess if the history of the market has any impact on the factors influencing the sectoremployees to carry over servers.

There is no sector in which workers and clients become similar to each other than in hospitality and leisure activities. Every business is as focused on its workers for consumer service as hospitality and leisure. Every guest interaction is a opportunity to distinguish the commodity, offer better quality, make a guest happy, receive a return client, and cross- or up-sell. Employees that are well trained, well equipped, have knowledge at their fingertips and are in a role to provide excellent guest experience with little distractions.Developing workers and providing them with tailored and efficient B2E approaches will improve employee career development and enhance workforce productivity. Additionally, it can reduce the training costs, cost of turnover, and transaction processing costs. The integration of Web technologies, cellular connectivity and web app solutions has provided a modern ability to provide staff, wherever, anywhere, with the right resources and knowledge.

\section{REFERENCES}

1. M. M. Rahim, M. Quaddus, and M. Singh, "Understanding the use of business-to-employee (B2E) portals in an Australian university though the management lens: A qualitative approach," in Encyclopedia of E-Business Development and Management in the Global Economy, 2010.

2. "DEVELOPPING AN E-COMMERCE MODEL (B2E) WITHIN A MULTI-SITE UNIVERSITY HEALTH CARE CENTER - A Solution to Promote Knowledge and Information Exchange," 2011, doi: 10.5220/0001780105080511.

3. M. M. Rahim, M. Quaddus, and M. Singh, "Understanding the Use of Business-to-Employee (B2E) Portals in an Australian University through the Employee Lens," in Global Business, 2011. 
4. R. Branquinho, "B2E portals - Analysis of the success factors in the portuguese banking sector," 2012, doi: 10.1145/2311917.2311920.

5. P. Lai, "THE LITERATURE REVIEW OF TECHNOLOGY ADOPTION MODELS AND THEORIES FOR THE NOVELTY TECHNOLOGY," J. Inf. Syst. Technol. Manag., 2017, doi: 10.4301/s1807-17752017000100002.

6. L. G. Wallace and S. D. Sheetz, “The adoption of software measures: A technology acceptance model (TAM) perspective,” Inf. Manag., 2014, doi: 10.1016/j.im.2013.12.003.

7. M. M. Rahim, M. Singh, and M. Quaddus, “Employee Attitudes towards Business-to-Employee (B2E) Portals Use," in Implementing New Business Models in For-Profit and Non-Profit Organizations, 2011.

8. M. Rahim, "Understanding adoption and impact of B2E e-business systems: lessons learned from the experience of an Australian university," J. Internet Commer., 2017

9. V. Guggisberg and A. Back, “Exploring innovation practices for B2E initiatives in the digital age,” 2018.

10. A. H. Abd-Elrahman et al., “Urbanization, Biodiversity and Ecosystem Services: Challenges and Opportunities,” Landsc. Urban Plan., 2012, doi: 10.1007/978-1-4020-4385-7. 

